\title{
Contents
}

\section{Part I A New Foundation of Physical Theories}

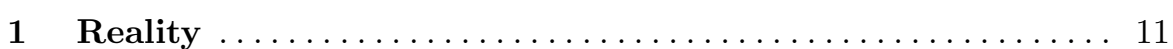

1.1 The Structure of Reality $\ldots \ldots \ldots \ldots \ldots \ldots \ldots \ldots \ldots \ldots \ldots$

1.2 The Physical Reality . . . . . . . . . . . . . . . . . 12

1.2.1 The Application Domain of a $P T \ldots \ldots \ldots \ldots \ldots 12$

1.2.2 The Fundamental Domain of a $P T \ldots \ldots \ldots \ldots \ldots$

1.2.3 The Reality Domain of a $P T \ldots \ldots \ldots \ldots \ldots \ldots$

1.2.4 The Reality Domain of all PTs ............. 14

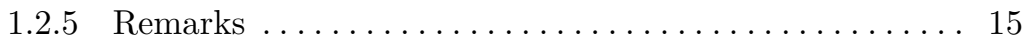

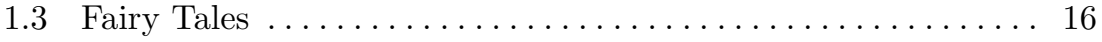

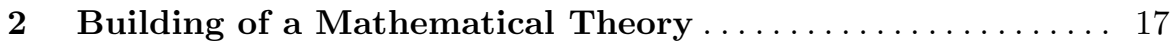

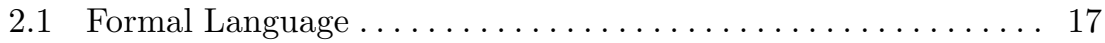

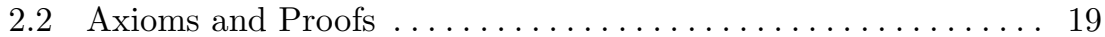

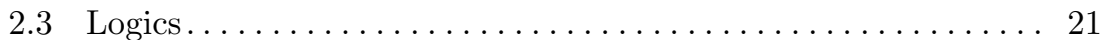

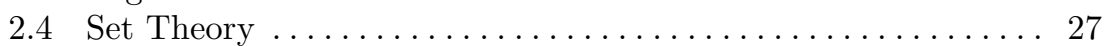

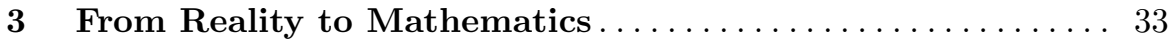

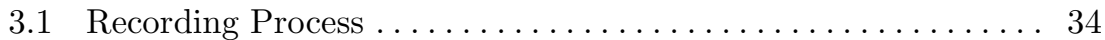

3.1.1 Basic Language . . . . . . . . . . . . . . . . . . . . . . . 34

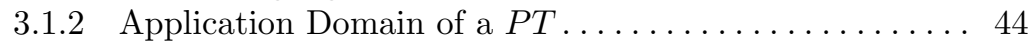

3.1 .3 Recording Rules....................... 44

3.1.4 Facts Recorded in the Basic Language ............. 45

3.2 Mathematization Process . . . . . . . . . . . . . . . . . . 46

3.2.1 The Basic Mathematical Theory ................. 46

3.2 .2 The Standard Mathematical Theory ............. 48

3.2.3 Enrichment of $M T_{\Theta}$ by $\bar{A} \ldots \ldots \ldots \ldots \ldots \ldots \ldots$ 


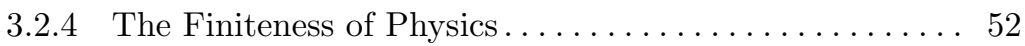

3.3 Idealization Process . . . . . . . . . . . . . . . . . 53

3.3.1 Transition from $M T_{\Theta}$ to $M T_{\Delta} \ldots \ldots \ldots \ldots \ldots \ldots \ldots \ldots$

3.3.2 Enrichment of $M T_{\Delta}$ by $\bar{A} \ldots \ldots \ldots \ldots \ldots \ldots \ldots \ldots$

3.3 .3 Fundamental Domain of a $P T \ldots \ldots \ldots \ldots$

4 Species of Structures and Axiomatic Basis

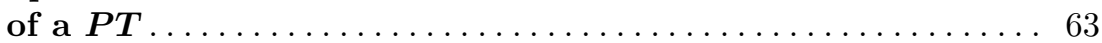

4.1 Mathematical Structures $\ldots \ldots \ldots \ldots \ldots \ldots \ldots \ldots \ldots \ldots \ldots \ldots 64$

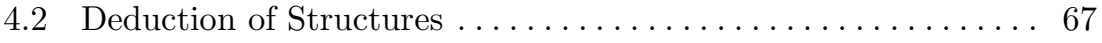

4.3 Axiomatic Basis and Fairy Tales................ 73

4.4 Pure Laws of Nature . . . . . . . . . . . . . . . . . . . 76

4.5 Change of the Mathematical Form of an

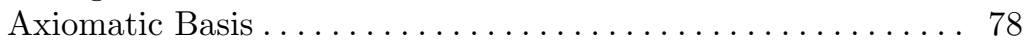

4.6 Inaccuracy Sets and Uniform Structures . . . . . . . . . . 85

4.7 Do the "Laws of Nature" Describe Realities? . . . . . . . . . . . . . 92

4.8 Classification of Laws of Nature . . . . . . . . . . . . . . 96

4.9 Skeleton and Uninterpreted Theories ................. 101

$5 \quad$ Relations Between Various PTs ..................... 105

5.1 Relations Between Two PTs with the Same Application

Domain . . . . . . . . . . . . . . . . . . . . . . . . . 106

5.2 Relations Between Two PTs with a Common Part of an

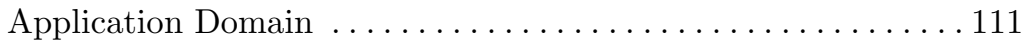

5.3 Pre-theories. . . . . . . . . . . . . . . . . . . . . . . . . 112

5.4 Relations Between PTs with Different Application Domains . . 116

5.5 Approximation Theories . . . . . . . . . . . . . . . . . . 117

5.6 The Network of PTs ...................... 118

6 Real and Possible as Physical Concepts ............... 121

6.1 Closed Theories . . . . . . . . . . . . . . . . . . . . . . . . . 124

6.2 Physical Systems . . . . . . . . . . . . . . . . . . . 128

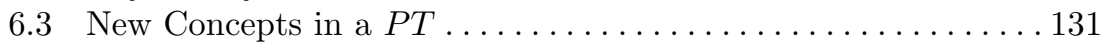

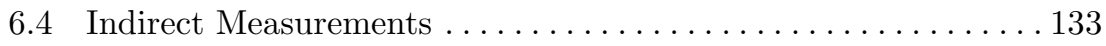

6.5 Classifications and Interpretations . . . . . . . . . . . . . . 138

6.6 The Reality Domain of a $P T \ldots \ldots \ldots \ldots \ldots \ldots \ldots \ldots$

Part II Examples of Simple Theories

A A Description of the Surface of the Earth,

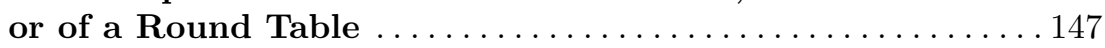

B A Simplified Example of Newton's Mechanics.... . . . . . . 159 
C The Structure of the Human Species $\ldots \ldots \ldots \ldots \ldots$

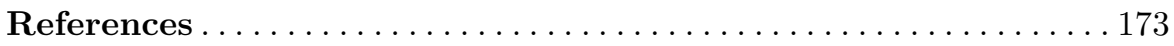

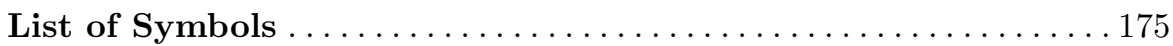

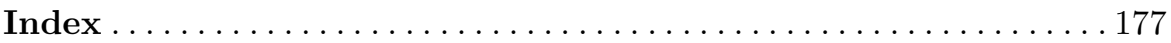

